Article

\title{
Improved Mechanical, Thermal, and Hydrophobic Properties of PLA Modified with Alkoxysilanes by Reactive Extrusion Process
}

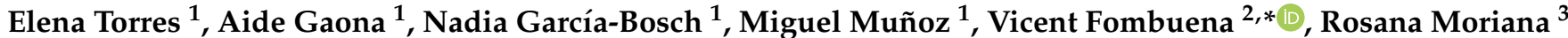 \\ and Ana Vallés-Lluch 4 (D)
}

Citation: Torres, E.; Gaona, A.; García-Bosch, N.; Muñoz, M.; Fombuena, V.; Moriana, R.; Vallés-Lluch, A. Improved Mechanical, Thermal, and Hydrophobic Properties of PLA Modified with Alkoxysilanes by Reactive Extrusion Process. Polymers 2021, 13, 2475. https://doi.org/ $10.3390 /$ polym 13152475

Academic Editors: Raluca Nicoleta Darie-Niță and Maria Râpă

Received: 29 June 2021

Accepted: 26 July 2021

Published: 27 July 2021

Publisher's Note: MDPI stays neutral with regard to jurisdictional claims in published maps and institutional affiliations.

Copyright: (C) 2021 by the authors. Licensee MDPI, Basel, Switzerland This article is an open access article distributed under the terms and conditions of the Creative Commons Attribution (CC BY) license (https:// creativecommons.org/licenses/by/ $4.0 /)$
1 Textile Industry Research Association (AITEX), Plaza Emilio Sala 1, 03801 Alcoy, Spain; etorres@aitex.es (E.T.); AGaona@aitex.es (A.G.); ngarcia@aitex.es (N.G.-B.); mmunoz@aitex.es (M.M.)

2 Technological Institute of Materials (ITM), Universitat Politècnica de València (UPV), Plaza Ferrándiz y Carbonell 1, 03801 Alcoy, Spain

3 Division of Bioeconomy and Health, RISE Research Institutes of Sweden, Drottning Kristinas väg 61, 11428 Stockholm, Sweden; rosana.moriana.torro@ri.se

4 Centre for Biomaterials and Tissue Engineering, Universitat Politècnica de València (UPV), Camí de Vera s/n, 46022 Valencia, Spain; avalles@ter.upv.es

* Correspondence: vifombor@upv.es

\begin{abstract}
An eco-friendly strategy for the modification of polylactic acid (PLA) surface properties, using a solvent-free process, is reported. Reactive extrusion (REX) allowed the formation of new covalent bonds between functional molecules and the PLA polymeric matrix, enhancing its mechanical properties and modifying surface hydrophobicity. To this end, the PLA backbone was modified using two alkoxysilanes, phenyltriethoxysilane and $\mathrm{N}$-octyltriethoxysilane. The reactive extrusion process was carried out under mild conditions, using melting temperatures between 150 and $180^{\circ} \mathrm{C}, 300 \mathrm{rpm}$ as screw speed, and a feeding rate of $3 \mathrm{~kg} \cdot \mathrm{h}^{-1}$. To complete the study, flat tapes of neat and functionalized PLA were obtained through monofilament melt extrusion to quantify the enhancement of mechanical properties and hydrophobicity. The results verified that PLA modified with $3 \mathrm{wt} \%$ of N-octyltriethoxysilane improves mechanical and thermal properties, reaching Young's modulus values of $4.8 \mathrm{GPa}$, and PLA hydrophobic behavior, with values of water contact angle shifting from $68.6^{\circ}$ to $82.2^{\circ}$.
\end{abstract}

Keywords: PLA; biopolymers; alkoxysilanes; hydrophobicity; grafting; monofilament melt extrusion; thermal properties; reactive extrusion

\section{Introduction}

The negative impact of plastics on human health and the environment is forcing the European Union to review the policy to reduce plastic waste. In 2018, European plastic production reached 61.8 million tonnes, being the global plastic production of 359 million tonnes [1]. Only 29.1 million tonnes of plastic waste were collected in the EU28+NO/CH to be treated. From 2006 to 2018, the amount of recycled plastic waste was doubled. However, $25 \%$ of plastic waste was still sent to landfills or in nature [2], from which a significant part was turned into marine litter, harming the environment. The use of biopolymers minimizes the adverse impact caused by conventional plastics because they are polymers able to be degraded to organic matter, such as water, carbon dioxide, and biomass once they up in the environment, which is a fact that decreases the accumulation of waste in the current landfills [3]. Therefore, the use of biodegradable polymers, with similar applications to conventional plastics, would be a desirable alternative to fossil-based polymers since the related environmental issues would be heavily minimized [4].

Currently, the production of biopolymers stands for about $1 \%$ of the total annual plastic production $[5,6]$. Nevertheless, due to social concern and the need to minimize 
dependence on fossil fuels, the biopolymers market is continuously growing with the estimated manufacture of 2.43 million tonnes for 2024 [7]. Polylactic acid (PLA) is one of the most demanded biopolymers, representing $13.9 \%$ of the global production of bioplastics [8], owing to its versatile characteristics [9], which make it applicable for packaging, textile, construction, and automotive applications. Specifically, in the textile industry, PLA is rapidly gaining importance due to its excellent mechanical properties when the polymer is processed into yarns $[10,11]$, being comparable to the commercial counterparts such as polyethylene (PE), polystyrene (PS), and polyethylene terephthalate (PET) [12,13]. Nonetheless, although PLA textiles exhibit excellent hand, moisture management, and easy-care properties [14], PLA fibers, unfortunately, are susceptible to degrade in wet conditions, which can be induced by the hydrolysis of ester bonds, leading to the decrease of the degree of polymerization [15]. Substantial research has suggested that PLA textiles undergo degradation during home laundering and storage; in such a way, there has been observed a $20 \%$ and $25 \%$ decrease in filament strength and modulus, respectively, after 10 times washing at $\mathrm{pH} 10,55^{\circ} \mathrm{C}$ [16]. Furthermore, a $50 \%$ decrease of the polymer $\mathrm{MW}$ was observed after 262 days of storage at $40{ }^{\circ} \mathrm{C}$ and $80 \%$ humidity [17]. Therefore, improving the hydrophobicity character of PLA fibers will enhance PLA resistance to hydrolysis, and hence, ameliorate its durability [18].

Additionally, in home textile applications, self-cleaning or easy-cleaning functionalities are usually required, which can be achieved by increasing the polymer surface hydrophobicity [19]. For instance, new materials with high hydrophobicity and durability properties have been developed through the formation of micro-thin super-slick hydrophobic surfaces preventing the adhesion of ice, dirt, debris, mold, snow, etc. [20]. In addition, within the textile market, self-cleaning added value functionalities are currently gaining importance. In order to achieve such functionalities, the most extended strategy is the application of coating or surface modification techniques [21]; however, the textile product loses its efficiency with the usages. Polymer functionalization with additives by compounding technology is another approach to obtain added value textiles. This process is based on a physical mixture of polymer and additive in the molten state [22]. Nevertheless, in many cases, the final product eventually loses the added functionality, since the additives migrate to the surface and are released to the environment [23]. Recently, reactive extrusion (REX) is being used to overcome the aforementioned drawbacks, considering that functional molecules are anchored into the polymeric matrix. REX technology provides stable and irreversible covalent bonds, achieving a uniform distribution of functional moieties into the polymer matrix and avoiding particle aggregation, migration, and leaching [24-26]. Furthermore, reactive extrusion offers a one-step solvent-free route to produce novel and high-performance materials with new functionalities [27]. Therefore, the REX process allows the incorporation of additives into the polymer matrix through covalent bonds under milder and environment-friendly conditions.

Accordingly, to improve PLA textile performance, new functionalities such as selfcleaning, dust removal, and durability can be granted to the biopolymer by the modification of PLA surface hydrophobicity [19]. Considering that this characteristic strongly depends on the surface free energy [28], it can be tuned by chemical modifications via reactive extrusion. Indeed, the incorporation of alkoxysilanes into polymeric matrices is proposed to modify their surface free energy and, consequently, their hydrophobicity [29-31]. Therefore, the use of biodegradable PLA and reactive extrusion as a processing method involves a cost-effective and environmentally friendly approach thanks to the extruder's unique stability as a vehicle for carrying out chemical reactions in the bulk phase; besides, it is a continuous process with low reaction times compared to batch processing and free-solvent, which contributes to minimizing the environmental footprint [32].

In the present study, PLA modifications through the grafting of alkoxy derivatives, using a single-step process (REX), are reported for conferring hydrophobicity to this biopolymer. Thereupon, the PLA matrix was covalently modified with two different alkylalkoxysilanes ( $\mathrm{R}^{\prime}$-Si-OR). The covalent incorporations were confirmed by ${ }^{1} \mathrm{H}$ NMR 
spectroscopy. Hydrophobic, thermal, and mechanical properties were studied after the obtention of flat tape samples through a conventional monofilament extrusion process.

\section{Materials and Methods}

\subsection{Materials and Reagents}

Polylactic acid (PLA) Ingeo ${ }^{\mathrm{TM}}$ 6201D with a number average molecular weight of $97,000 \mathrm{~g} \cdot \mathrm{mol}^{-1}\left(\mathrm{M}_{\mathrm{n}}\right)$ was provided by NatureWorks LLC (Minnetonka, MN, USA), which has a range melting temperature from 155 to $170{ }^{\circ} \mathrm{C}$. In order to develop hydrophobic PLA, different alkoxy derivatives were employed. Specifically, phenyltriethoxysilane, $\mathrm{Ph}$ $\mathrm{Si}(\mathrm{OEt})_{3}$, with a minimum purity of $98 \%$, was supplied by Sigma-Aldrich (Madrid, Spain). A second organosilane, N-octyltriethoxysilane, Oct-Si $(\mathrm{OEt})_{3}$, with a purity of $97 \%$ was supplied by abcr GmbH (Karlsruhe, Germany).

\subsection{Sample Preparation}

\subsubsection{Reactive Extrusion}

In the reactive melt processing, a screw speed of $300 \mathrm{rpm}$, feed rate of $3 \mathrm{~kg} \cdot \mathrm{h}^{-1}$, and profile temperature between 150 and $180{ }^{\circ} \mathrm{C}$ were set as optimal extrusion conditions. According to previous experience and knowing that around $0.3 \mathrm{wt} \%$ of alkylalkoxysilane corresponds to the theoretical stoichiometry, which considers that each PLA hydroxyl (-OH) end-group reacts with one alkoxy end-group from the alkoxysilanes (1:1), the exchange reaction yield obtained was very low. Accordingly, the alkoxysilane molar concentration was estimated considering that, with less than $50 \%$ probability, only one alkoxy end-group from alkoxysilanes reacts with one PLA hydroxyl (-OH) end-group (3:1), corresponding to $1.3-1.5 \mathrm{wt} \%$ depending on the organosilane molar mass (Table 1). Thus, 1.3 and $3.0 \mathrm{wt} \%$ were established as suitable mass concentrations. On the other hand, having the limitation of a minimum flow rate of $0.4 \mathrm{~mL} \cdot \mathrm{min}^{-1}$ provided by the HPLC pump, it was not possible to perform the reaction process with mass concentrations lower than $0.8 \mathrm{wt} \%$ in order to guarantee the residence time required. Such alkoxysilanes were introduced without solvent dilution using an HPLC pump. Thus, Table 1 summarizes the functionalized PLA samples obtained by the reactive extrusion approach. In a typical experiment, neat PLA pellets were dried in a vacuum oven overnight at $75^{\circ} \mathrm{C}$ and then extruded with different percentages of alkoxysilanes, according to Table 1 , in a twin-screw extruder (Leistritz ZSE 18 , Nuremberg, Germany) with L/D $=68$ ( $\mathrm{L}$ and $\mathrm{D}=18 \mathrm{~mm}$ are the length and diameter of the screw, respectively). The material was subsequently cooled in a water bath and pelletized. The obtained pellets were dried in a vacuum oven overnight at $75{ }^{\circ} \mathrm{C}$ in order to remove the remaining water.

Table 1. Functionalized PLA samples through reactive extrusion.

\begin{tabular}{|c|c|c|c|}
\hline Sample & $\begin{array}{c}\text { Functional Molecule } \\
\left(\mathbf{R}^{\prime}\right)\end{array}$ & $\begin{array}{c}\text { Concentration } \\
(w t \%)\end{array}$ & $\begin{array}{c}\text { Molar Concentration } \\
(\mathrm{mol} / \mathrm{h})\end{array}$ \\
\hline PLA (control) & - - - - - & $-\ldots-\ldots$ & 0.031 \\
\hline O-PLA-A & Oct-Si(OEt $)_{3}$ & 1.5 & 0.167 \\
\hline O-PLA-B & Oct-Si(OEt) & 3.0 & 0.337 \\
\hline P-PLA-A & $\mathrm{Ph}-\mathrm{Si}(\mathrm{OEt})_{3}$ & 1.3 & 0.167 \\
\hline P-PLA-B & $\mathrm{Ph}-\mathrm{Si}(\mathrm{OEt})_{3}$ & 2.7 & 0.337 \\
\hline
\end{tabular}
rate $=3 \mathrm{~kg} \cdot \mathrm{h}^{-1}$, and alkoxysilane flow rates $=0.4-1.5 \mathrm{~mL} \cdot \mathrm{min}^{-1}$.

\subsubsection{Flat Tape Extrusion}

New functionalized PLA materials, developed by REX, were subsequently processed in a monofilament extrusion pilot plant to obtain flat tape samples. This pilot plant is composed of four basic elements/stages: single-screw extruder, spinning die, drawing unit composed by godets, ovens and cooling baths, and a winder. More specifically, the extrusion unit is formed by a melt pump, which works at flow rates inferior to $3 \mathrm{~kg} \cdot \mathrm{h}^{-1}$, 
and a single-screw extruder with a diameter of $25 \mathrm{~mm}$ and $\mathrm{L} / \mathrm{D}=24: 1$. Finally, flat tapes were prepared using the conditions specified in Table 2.

Table 2. Melt extrusion conditions for flat tape processing using monofilament melt spinning technology.

\begin{tabular}{ccccc}
\hline Sample & $\mathbf{V}_{\text {godet1 }}(\mathbf{m} / \mathbf{m i n})$ & $\mathbf{V}_{\text {godet4 }}(\mathbf{m} / \mathbf{m i n})$ & $\begin{array}{c}\text { Draw Ratio } \\
\text { (DR) }\end{array}$ & $\begin{array}{c}\text { Dimensions (Width } \\
\times \text { Thickness, mm) }\end{array}$ \\
\hline PLA & 10 & 45 & 4.5 & $2.70 \times 0.14$ \\
O-PLA-A & 10 & 55 & 5.5 & $2.34 \times 0.13$ \\
O-PLA-B & 10 & 66 & 6.6 & $2.40 \times 0.14$ \\
P-PLA-A & 10 & 55 & 5.5 & $2.32 \times 0.13$ \\
P-PLA-B & 10 & 62 & 6.2 & $2.20 \times 0.14$ \\
\hline
\end{tabular}

Flat tape extruding conditions: Temperature profile $=195 / 205 / 205 / 220 / 215^{\circ} \mathrm{C}$, Flow rate $=1 \mathrm{~kg} \cdot \mathrm{h}^{-1}$, Cooling bath temperature $=35^{\circ} \mathrm{C}$ and Godet speed range $=10-66 \mathrm{rpm}$.

\subsubsection{Characterization Methods}

Total silicon contents in flat tape samples were obtained by inductively coupled plasma optical emission spectroscopy (ICP-OES), using an Agilent 5110 equipment (Santa Clara, CA, USA). The average values and standard deviations were calculated measuring five replicates per sample. The total integrity and covalent incorporation of functional alkoxysilanes were determined by liquid-state ${ }^{1} \mathrm{H}$ NMR spectroscopy. High-resolution liquid-state ${ }^{1} \mathrm{H}$ NMR spectroscopy measurements were carried out with a Bruker AV400 instrument (Mannheim, Germany) working at $300 \mathrm{MHz}$. The analyses were performed using approximately $20 \mathrm{mg}$ of sample and dissolved in $0.6 \mathrm{~mL}$ of deuterated chloroform (Sigma-Aldrich, Madrid, Spain). Chemical shifts were quoted in ppm and referred to internal tetramethylsilane (TMS).

Neat and functionalized PLA were characterized by size exclusion chromatography by a high-performance liquid chromatography photodiode array detection method using a uHPLC 1260 Infinity Binary LC System (Santa Clara, Agilent). In a typical analysis, samples were dissolved in chloroform as elution solvent, with a $2 \mathrm{wt} \%$ concentration and filtered through $0.22 \mu \mathrm{m}$ pore size PTFE filters prior to measurements. Number-average $\left(\mathrm{M}_{n}\right)$ weight-average $\left(\mathrm{M}_{\mathrm{w}}\right)$ molar masses and dispersities $(D)$ were obtained from a calibration curve based on polystyrene (PS) standards. Empower 3 was used for processing data.

Differential scanning calorimetry (DSC) analyses were carried out $\left(50 \mathrm{~mL} \cdot \mathrm{min}^{-1}\right.$ of nitrogen atmosphere, $99.99 \%$ purity) in a DSC 3+/Mettler Toledo (Barcelona, Spain). Measurements to determine the melting and crystallization behavior of neat and functionalized PLA were performed by encapsulating 10-12 $\mathrm{mg}$ of sample in an aluminum pan and following this temperature program: (i) heating from 30 to $170{ }^{\circ} \mathrm{C}$, corresponding to the holding temperature, $\mathrm{T}_{\text {hold }}$, (ii) isothermal step of $2 \mathrm{~min}$ at $\mathrm{T}_{\text {hold }}$ to remove thermal history, (iii) cooling ramp from $\mathrm{T}_{\text {hold }}$ to $-30{ }^{\circ} \mathrm{C}$ and, (iv) heating ramp from -30 to $250{ }^{\circ} \mathrm{C}$. All tests were performed at a heating/cooling rate of $20^{\circ} \mathrm{C} \cdot \mathrm{min}^{-1}$. As the previous thermal history was removed, the crystallization temperature $\left(\mathrm{T}_{\mathrm{c}}\right)$ was established from cooling scans, whereas the glass transition temperature $\left(T_{g}\right)$ and melting temperatures $\left(T_{m}\right)$ were determined using the information provided by the second heating scan. The degree of crystallinity $\left(X_{c}\right)$ was calculated in the first heating program by means of Equation (1), where $\Delta \mathrm{H}_{\mathrm{m}}$ is the melting enthalpy of PLA $\left(\mathrm{J} \cdot \mathrm{g}^{-1}\right), \Delta \mathrm{H}_{\mathrm{mc}}$ corresponds to the cold crystallization enthalpy of PLA $\left(\mathrm{J} \cdot \mathrm{g}^{-1}\right), \Delta \mathrm{H}^{0}{ }_{\mathrm{m}}$ is the melting enthalpy associated with a theoretically fully crystalline PLA, reported to be $93 \mathrm{~J} \cdot \mathrm{g}^{-1}[33,34]$, and $x$ is the the proportion of pure PLA in the different samples with additives:

$$
\mathrm{X}_{\mathrm{c}}(\%)=\left[\frac{\Delta \mathrm{H}_{\mathrm{m}}-\Delta \mathrm{H}_{\mathrm{mc}}}{\Delta \mathrm{H}_{\mathrm{m}}^{0} \cdot \mathrm{x}}\right] \cdot 100
$$

Thermogravimetric analyses (TGA) were conducted under nitrogen atmosphere $\left(50 \mathrm{~mL} \cdot \mathrm{min}^{-1}\right)$ with a Mettler Toledo TGA/SDTA 851E analyzer (Barcelona, Spain). In all cases, $8 \mathrm{mg}$ of sample were heated at $10{ }^{\circ} \mathrm{C} \cdot \mathrm{min}^{-1}$ from 25 to $700{ }^{\circ} \mathrm{C}$. 
Mechanical characterization of flat tapes was performed by tensile tests. Mechanical trials were carried out at room temperature with an INSTRON 3343-K7523 (Barcelona, Spain) machine following UNE EN ISO 13934-1. Samples were tested using $0.5 \mathrm{kN}$ load cell a crosshead speed of $50 \mathrm{~mm} \cdot \mathrm{min}^{-1}$ and a distance between clamps of $50 \mathrm{~mm}$. Typically, to achieve an accurate average value of tensile strength, Young's modulus, and elongation at break, at least five repetitions of each sample were performed following UNE EN ISO 13934-1 recommendations.

Changes in the wetting properties of functionalized PLA were determined by water contact angle measurements (WCA) on the sample's dry surfaces by the sessile drop technique. Neat PLA was used as control. An EasyDrop Standard goniometer, model FM140 supplied by KRÜSS (KRÜSS GmbH, Hamburg, Deutschland), with a measurement range from $1^{\circ}$ to $180^{\circ}$ and precision of $\pm 0.1^{\circ}$ was used for this purpose. The equipment was supplemented with a video capture kit and analysis software (Drop Shape Analysis SW21; DSA1). Five replicates of each sample were tested, performing 10 measurements for each replicate, and calculating the mean value from 50 values per sample with a standard deviation lower than $3 \%$.

\section{Results}

\subsection{PLA/Alkoxysilanes Reaction}

The reaction between $\mathrm{R}^{\prime}$-alkoxysilanes $\left(-\mathrm{R}^{\prime}=\right.$ phenyl or octyl) and PLA through hydroxyl (-OH) end groups was expected to lead to the formation of $\mathrm{R}^{\prime}-\mathrm{Si}-\mathrm{PLA}$ by exchange reactions, as shown in Figure $1[23,35]$.

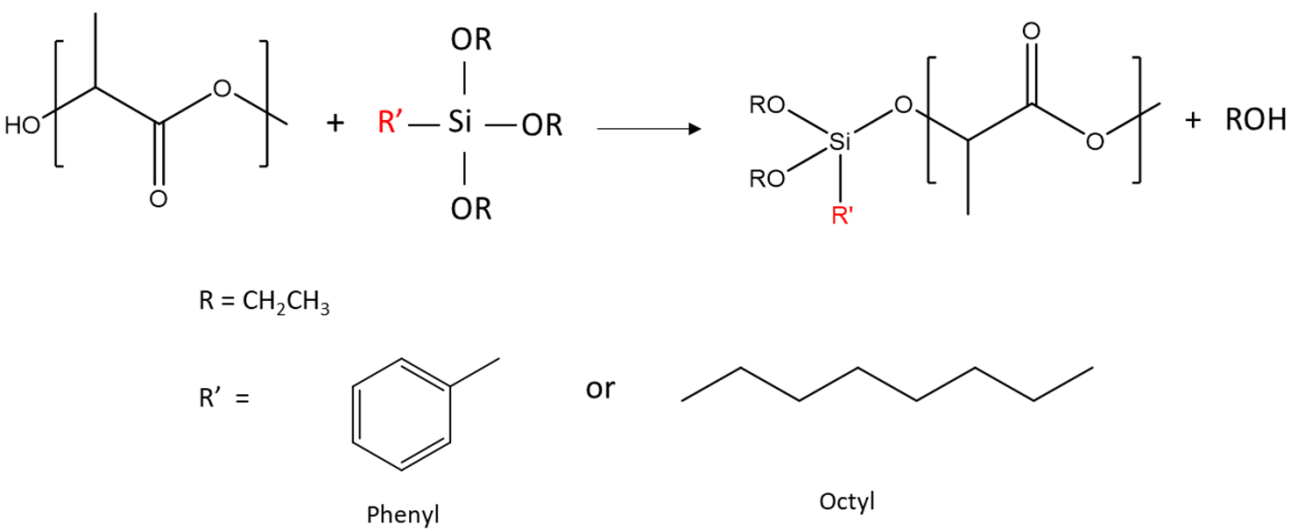

Figure 1. Reaction schemes between PLA hydroxyl end groups and alkoxysilanes. Only OR exchange is shown here.

After chemical modification of neat PLA, ICP-OES analyses were performed to determine total silicon contents into the PLA matrix (grafted and non-grafted). More specifically, Table 3 shows concentration (ppm) and weight percentage of silicon into a functionalized PLA matrix, as well as the incorporation ratio of organosilane units (\%), which are calculated from the ratio between experimental and theoretical silicon contents.

Table 3. Chemical analyses of functionalized PLA flat tapes determined by ICP-OES.

\begin{tabular}{cccc}
\hline Sample & Concentration $(\mathbf{p p m})$ & Si $\mathbf{( \% )}$ & Incorporation $\left.^{(\%)}\right)^{\mathbf{a}}$ \\
\hline O-PLA-A & $259 \pm 16$ & 0.026 & 16.6 \\
O-PLA-B & $364 \pm 22$ & 0.036 & 12.2 \\
P-PLA-A & $727 \pm 55$ & 0.073 & 48.2 \\
P-PLA-B & $1594 \pm 410$ & 0.159 & 50.4
\end{tabular}

a Incorporation percentage calculated as the ratio between the experimental and theoretical concentration of silicon atoms in the PLA matrix ( $w \mathrm{t} \%)$. 
Table 3 shows the presence of alkoxysilanes in the PLA polymeric matrix. Silicon weight percentage on the final samples was much higher for PLA modified with phenyltriethoxysilane (P-PLA-A and P-PLA-B) than PLA modified with octyltriethoxysilane (O-PLA-A and O-PLA-B). Therefore, it can be presumed that the reaction is affected by steric factors [36], where pendant octyl groups are subjected to higher steric hindrance, hampering the exchange reaction between PLA hydroxyl end-group and the organosilane. In this sense, the length of Si-octyl (8.54 $\AA$ ) and Si-phenyl (4.24 $\AA$ ) was predicted through ChemDraw software to support such an assumption.

Notwithstanding, ICP analyses only confirmed the presence of silicon species into the polymeric matrix but did not provide accurate information about new covalent bonds formed between the PLA backbone and alkoxy derivatives. To this end, the efficient anchoring of these alkoxy derivatives, by a reactive extrusion process, was verified by the liquid ${ }^{1} \mathrm{H}$ NMR technique. Figure 2 shows the reaction scheme between PLA and N-octyltriethoxysilane (Figure 2a), as well as the ${ }^{1} \mathrm{H}$ NMR spectra for functionalized (O-PLA-A and O-PLA-B) and neat PLA samples (Figure 2b). According to the literature [37,38], the PLA spectrum revealed four main signals at 1.6, 5.2, 1.4 , and $4.3 \mathrm{ppm}$, which correspond to $\mathrm{CH}_{3}(\mathrm{a}), \mathrm{CH}(\mathrm{b})$, $\mathrm{CH}_{3}(\mathrm{c}+\mathrm{r})$, and $\mathrm{CH}(\mathrm{d})$ next to the terminal groups, respectively [39,40]. However, when PLA was modified with Oct-Si $(\mathrm{OEt})_{3}$, new signals associated to N-octyltriethoxysilane were detected. In this sense, signals at 1.2, 0.9 , and 0.6 ppm were observed when alkoxysilane was incorporated. More specifically, chemical shifts at 1.2 were assigned to protons $\mathrm{p}$ and $\mathrm{f}-\mathrm{k}$ from unreacted ethoxy groups $\left(\mathrm{CH}_{3}, \mathrm{p}\right)$ and the octyl chain $(\mathrm{f}-\mathrm{k})$. On the other hand, signals at 0.9 and $0.6 \mathrm{ppm}$ were assigned to the terminal $\mathrm{CH}_{3}(\mathrm{l})$ and the methylene was linked to silicon $\mathrm{CH}_{2}$ (e) (Figure 2a). Moreover, a new quadruplet appeared at 3.8 ppm (Figure 2b), being assigned to the methylene group $\left(\mathrm{CH}_{2} \mathrm{O}\right)$ of unreacted alkoxysilane ethoxy groups $(\mathrm{m}$, Figure 2a). This result was expected, as the ethoxy groups were introduced in large excess compared to the terminal hydroxyl functions of PLA. Therefore, these chemical signals confirmed the presence of alkoxysilane into a PLA matrix, whereas the formation of new covalent bonds through PLA hydroxyl end groups was evidenced with the appearance of a chemical shift at $3.7 \mathrm{ppm}\left(\mathrm{d}^{\prime}\right)$, which was assigned to the resonance modification of the terminal methine group in the $\alpha$-position of the hydroxyl function (Figure 2a). Thus, signal d shifted, from 4.2 (d) to $3.7 \mathrm{ppm}\left(\mathrm{d}^{\prime}\right)$, due to the modification of a methine group chemical environment. Such a chemical signal is shifted compared to the value observed from starting PLA, which indicates that the reagent is no more in its initial form once the alkoxysilane is covalently incorporated (see inset, Figure 2). Therefore, the presence of this new quadruplet (3.7 ppm, $\mathrm{d}^{\prime}$ ) and the complete disappearance of a $\mathrm{d}$ signal (4.2 ppm) confirmed the formation of covalent bonds between the PLA matrix and N-octyltriethoxysilane by exchange reactions.

On the other hand, the integration of proton signals from the modified methine group in the $\alpha$-position of the hydroxyl function $\left(\mathrm{d}^{\prime}\right)$ and signal of the unreacted ethoxy group (p) was used to estimate the evolution of grafting reaction, corresponding to the $\mathrm{d}^{\prime} / \mathrm{p}$ ratio (Table 4). By integrating chemical shifts, we found a clear limitation in the reaction yield between alkoxy units (-OR) and PLA hydroxyl (-OH) end groups, as well as an excess of reactive ethoxy end groups, as the $\mathrm{d}^{\prime} / \mathrm{p}$ ratio decreased when the octylalkoxysilane concentration was increased. Additionally, the doublet at $1.4 \mathrm{ppm}$ and $1.5 \mathrm{ppm}$ assigned to $\mathrm{CH}_{3}$ (c) next to the terminal -OH group and $\mathrm{CH}_{3}$ (r) next to the terminal -COOH group, respectively, disappeared when $1.5 \mathrm{wt} \%$ of $\mathrm{N}$-octyltriethoxysilane was added to the PLA matrix, implying that the reaction proceeds through both terminal groups. However, when the percentage of N-octyltriethoxysilane was increased up to $3.0 \mathrm{wt} \%$ (O-PLA-B), the doublet assigned to $\mathrm{CH}_{3}(\mathrm{r})$ next to the terminal $-\mathrm{COOH}$ group remains visible, suggesting that the reaction proceeds mainly through PLA hydroxyl $(-\mathrm{OH})$ end groups [35]. However, other side reactions cannot be excluded, such as transesterifications reactions through the PLA carboxylic acid (-COOH) end groups or in situ condensation of the organosilane. 


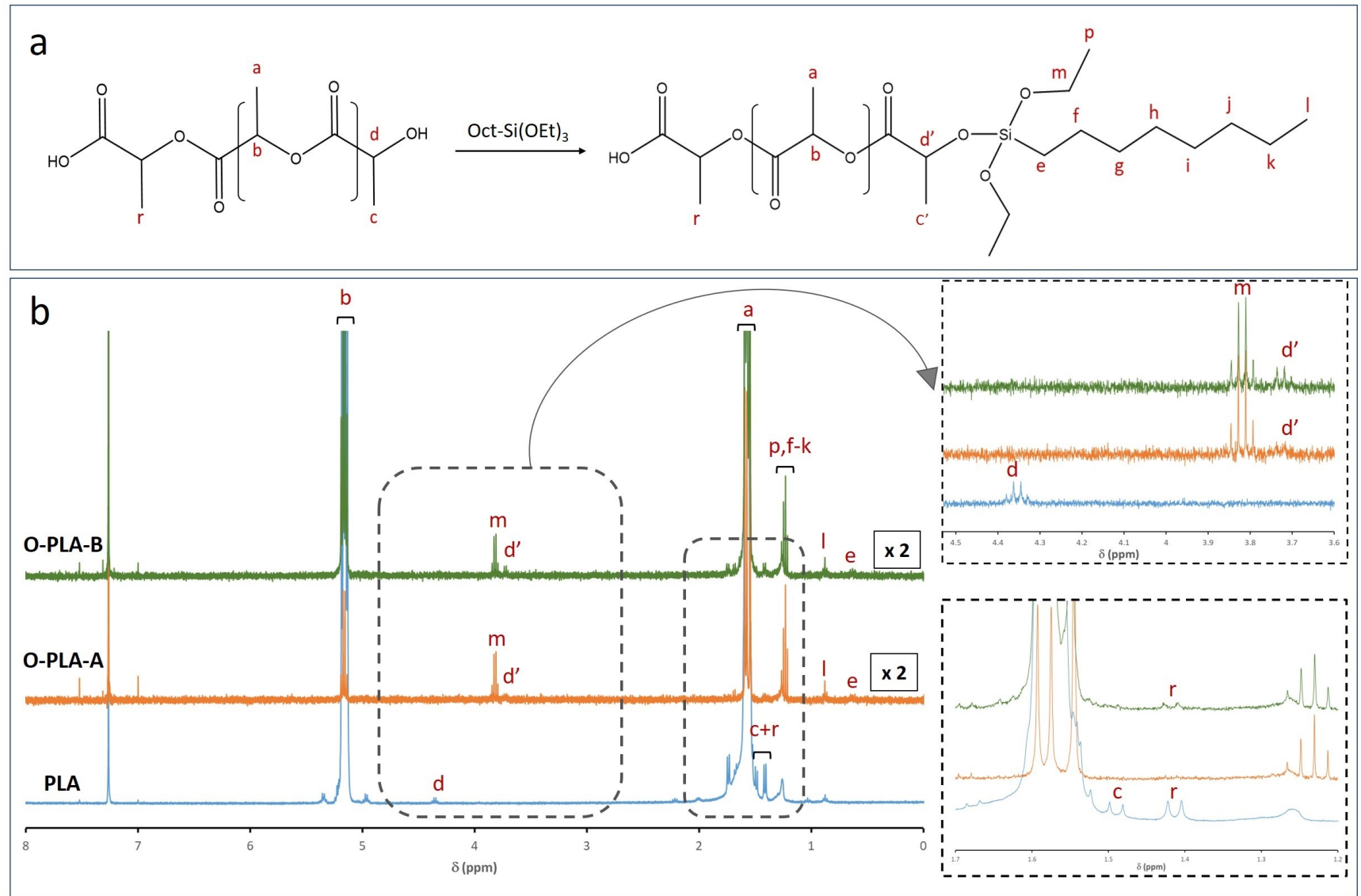

Figure 2. (a) Reaction scheme for PLA modification with N-octyltriethoxysilane and (b) ${ }^{1} \mathrm{H} N M R$ of neat and functionalized PLA with different concentrations of N-octyltriethoxysilane: O-PLA-A (1.5 wt \%) and O-PLA-B (3.0 wt $\%)$.

Table 4. Chemical shifts and integration signal values.

\begin{tabular}{cccc}
\hline Sample ID & Assignment & Chemical Signal (ppm) & Integration $^{\mathbf{a}}$ \\
\hline \multirow{2}{*}{ O-PLA-A } & $\mathrm{d}^{\prime}$ & 3.7 & 1 \\
& $\mathrm{p}$ & 1.21 & 9.58 \\
\hline \multirow{2}{*}{ O-PLA-B } & $\mathrm{d}^{\prime}$ & 3.7 & 1 \\
& $\mathrm{p}$ & 1.21 & 12.61 \\
\hline \multirow{2}{*}{ P-PLA-A } & $\mathrm{d}^{\prime}$ & 3.7 & 1 \\
& $\mathrm{p}$ & 1.21 & 3.45 \\
\hline \multirow{2}{*}{ P-PLA-B } & $\mathrm{d}^{\prime}$ & 3.7 & 1 \\
& $\mathrm{p}$ & 1.21 & 6.59 \\
\hline
\end{tabular}

a Values obtained from the integration of the $\mathrm{d}^{\prime}$ and $\mathrm{p}$ chemical shifts using MestreNova software.

Comparable effects were observed when PLA was modified with phenyltriethoxysilane (Figure 3). In the case of P-PLA-A and P-PLA-B samples, chemical shifts assigned to phenyl organic fragments were revealed between 7 and $7.5 \mathrm{ppm}(\mathrm{e}-\mathrm{i})$. Likewise, the spectra depicted a new proton signal at $3.7 \mathrm{ppm}\left(\mathrm{d}^{\prime}\right)$, confirming the resonance modification of the terminal methine group in the $\alpha$-position of the hydroxyl function. Similar to O-PLA samples, the total disappearance of the signal related to methine next to the terminal group ( $\mathrm{d}, 4.2 \mathrm{ppm})$ verified the phenyltriethoxysilane incorporation by exchange reactions. On the other hand, new signals at $1.3(\mathrm{p})$ and $3.8 \mathrm{ppm}(\mathrm{m})$, associated with the unreacted ethoxy groups, were detected and integrated. Accordingly, the $\mathrm{d}^{\prime} / \mathrm{p}$ ratio suggested a higher reactivity of terminal ethoxy groups from phenyltriethoxysilane than octyltriethoxysilane, as the signal intensity associated with unreacted ethoxy groups $(p)$ was considerably lower for P-PLA-samples than O-PLA-samples (Table 4). Inferior inten- 
sities for the $\mathrm{p}$ signal are associated with higher reaction yield, whether due to exchange reactions or organosilane hydrolysis/self-condensation in situ during the process. The high incorporation observed by ICP analysis and the remaining presence of signals at 1.4 and $1.5 \mathrm{ppm}$, assigned to $\mathrm{CH}_{3}$ (c) next to the terminal -OH group and $\mathrm{CH}_{3}(\mathrm{r})$ next to the terminal - $\mathrm{COOH}$ group, respectively, suggested that the hydrolysis and self-condensation of phenyltriethoxysilane molecules also occurred in situ during the reactive extrusion process, leading to the formation of highly condensed silicon species (inset Figure 3). Therefore, the reactive extrusion process allowed both alkoxysilane hydrolysis-condensation and exchange reactions through terminal hydroxyl and ester functions. However, the doublet assigned to $\mathrm{CH}_{3}$ (r) next to the terminal - $\mathrm{COOH}$ group remains visible for P-PLA samples, suggesting that the exchange reaction proceeds mainly through PLA hydroxyl $(-\mathrm{OH})$ end groups. More information about the reaction scheme of the PLA modification with (3-glycidyloxypropyl)trimethoxysilane, phenyltriethoxysilane and titanium phenoxide can be found in the Supplementary Materials (Figures S1 and S2).

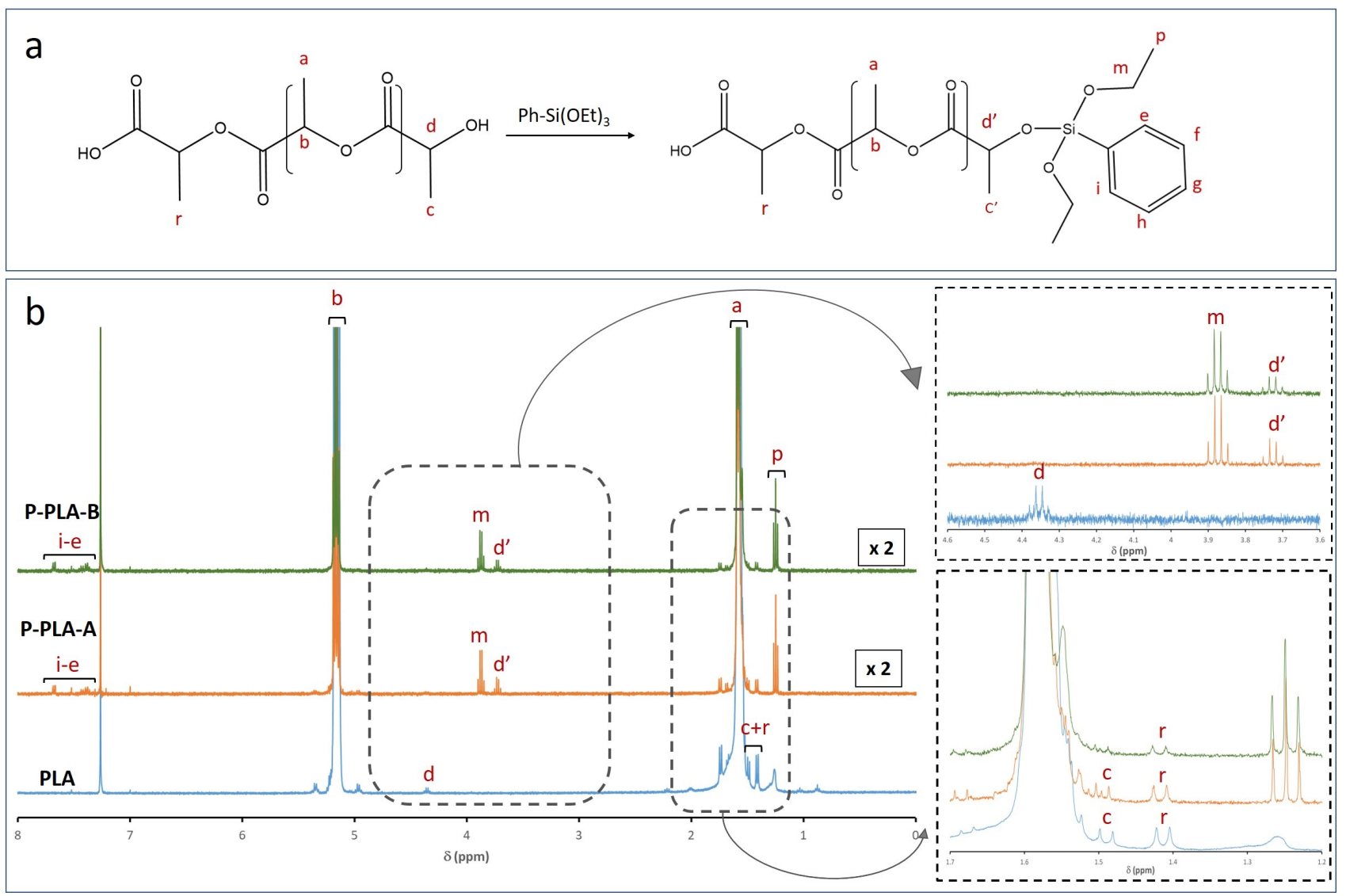

Figure 3. (a) Reaction scheme for PLA modification with phenyltriethoxysilane and (b) ${ }^{1} \mathrm{H}$ NMR of neat and functionalized PLA with different phenyltriethoxysilane concentrations: P-PLA-A (1.3 wt $\%)$ and P-PLA-B (2.7 wt $\%)$.

Aiming at verifying such hypotheses, a deeper investigation on the effect of alkylalkoxysilane incorporation on PLA molar mass was performed by size exclusion chromatography (SEC) experiments. SEC results for neat and functionalized PLA are shown in Table 5. As reported in the literature, PLA is susceptible to thermal degradation during the melt extrusion process, leading to a decrease in $\mathrm{M}_{\mathrm{W}}$, rheological, and mechanical properties [41,42]. Accordingly, after PLA extrusion processing, the results showed a decrease in $\mathrm{M}_{\mathrm{n}}$ (from 97,000 to $75,000 \mathrm{~g} \cdot \mathrm{mol}^{-1}$ ) and $\mathrm{M}_{\mathrm{w}}$ (from 173,000 to $116,000 \mathrm{~g} \cdot \mathrm{mol}^{-1}$ ), suggesting the molecular degradation of PLA. In the same way, SEC results for functionalized PLA with Octyl-Si(OEt $)_{3}$ evidenced the highest reduction in molar mass values, which may be attributed to chain scissions induced by ester-alkoxysilane exchange reactions at high temperatures $[23,38]$. In the case of phenyltriethoxysilane, only a slight reduction in SEC 
values was observed despite the higher presence of alkoxysilane species, such as those previously evidenced by ICP (Table 3).

Table 5. SEC analysis on neat and functionalized PLA with different alkoxysilane concentrations.

\begin{tabular}{cccc}
\hline Sample & $\mathbf{M}_{\mathbf{n}}\left(\mathbf{g} \cdot \mathbf{m o l}^{-\mathbf{1}}\right)$ & $\left.\mathbf{M}_{\mathbf{w}} \mathbf{( g} \cdot \mathbf{m o l} \mathbf{l}^{-\mathbf{1}}\right)$ & $\mathbf{D}$ \\
\hline Neat PLA & $97,000 \pm 20,000$ & $173,000 \pm 20,000$ & 1.85 \\
Extruded PLA & $75,000 \pm 20,000$ & $116,000 \pm 20,000$ & 1.56 \\
O-PLA-A & $48,000 \pm 6000$ & $94,000 \pm 6000$ & 1.96 \\
O-PLA-B & $45,000 \pm 9000$ & $90,000 \pm 15,000$ & 1.99 \\
P-PLA-A & $61,000 \pm 6000$ & $101,000 \pm 4000$ & 1.66 \\
P-PLA-B & $66,000 \pm 4000$ & $117,000 \pm 2000$ & 1.62 \\
\hline
\end{tabular}

\subsection{Characterization of the Functionalized Polymers}

Thermal properties of functionalized PLA flat tape samples were studied taking neat PLA as a reference. Glass transition and melting endotherms registered during the second heating scan are shown in Figure 4. All curves exhibited small glass transition temperature peaks $\left(\mathrm{T}_{\mathrm{g}}\right)$ and a broad melting endotherm signal $\left(\mathrm{T}_{\mathrm{m}}\right)$. More specifically, neat PLA flat tape displayed two small glass transition temperature peaks, which are directly related to polymeric chain movement, at $\mathrm{T}_{\mathrm{g} 1}=71^{\circ} \mathrm{C}$ and $\mathrm{T}_{\mathrm{g} 2}=82^{\circ} \mathrm{C}$ (Figure 4, Table 6). The presence of two glass transition peaks may be associated with the formation of two regions with different crystallinity levels as a result of the drawing process. After grafting $1.5 \mathrm{wt} \%$ of octyltriethoxysilane and $1.3 \mathrm{wt} \%$ of phenyltriethoxysilane, both peaks were slightly shifted toward higher temperatures. Interestingly, when $3.0 \mathrm{wt} \%$ of octyltriethoxysilane and $2.7 \mathrm{wt} \%$ of phenyltriethoxysilane were incorporated through a reactive extrusion process, only one glass transition peak was observed at lower temperatures $\left(<70{ }^{\circ} \mathrm{C}\right)$. This thermal effect on functionalized flat tapes suggested a lubricant effect at high concentrations of alkoxysilanes, which enabled a greater segmental motion and chain sliding, requiring thus lower stress forces for both processes [43]. Regarding melting temperature, the second heating scan provided similar melting curves for PLA and functionalized samples, where a wide melting peak around $170^{\circ} \mathrm{C}$ was obtained. However, samples with low alkoxysilane concentrations, O-PLA-A and P-PLA-A, displayed a small shoulder overlapped to the melting peak (highlighted in the Figure 4 with a circumference), which is associated with the fusion of imperfect grown crystals, whereas large melting peaks are related to highly ordered crystalline structures formed after drawing stages $[23,44,45]$. Therefore, flat tape samples with low alkoxysilane concentrations showed two regions with different crystallinity, while high contents provided a homogeneous crystal region, probably as a result of the appearance of nucleating points, which induced a more uniform crystal growth [41], and a lubricant effect that enabled a higher and homogeneous drawing treatment.

Table 6. DSC characteristic parameters of neat and functionalized PLA flat tapes by reactive extrusion.

\begin{tabular}{cccccc}
\hline Sample & $\mathbf{T}_{\mathbf{g} \mathbf{1}}\left({ }^{\circ} \mathbf{C}\right)$ & $\mathbf{T}_{\mathbf{g} \mathbf{2}}\left({ }^{\circ} \mathbf{C}\right)$ & $\mathbf{T}_{\mathbf{m}}\left({ }^{\circ} \mathbf{C}\right)$ & $\Delta \mathbf{H}_{\mathbf{m}}\left(\mathbf{J} \cdot \mathbf{g}^{-\mathbf{1})}\right.$ & $\mathbf{X}_{\mathbf{c}}(\mathbf{\%})^{\mathbf{a}}$ \\
\hline PLA & 71 & 82 & 168 & 43.8 & 47 \\
O-PLA-A & 72 & 88 & 170 & 48.4 & 52 \\
O-PLA-B & 67 & --- & 169 & 52.6 & 56 \\
P-PLA-A & 72 & 82 & 171 & 48.1 & 51 \\
P-PLA-B & 69 & --- & 170 & 48.4 & 52 \\
\hline
\end{tabular}

${ }^{a}$ Crystallinity was estimated according to the ratio between the heat of fusion $\left(\mathrm{J} \cdot \mathrm{g}^{-1}\right)$ measured and tabulated value for $100 \%$ crystalline PLA $\left(93.0 \mathrm{~J} \cdot \mathrm{g}^{-1}\right)$. 


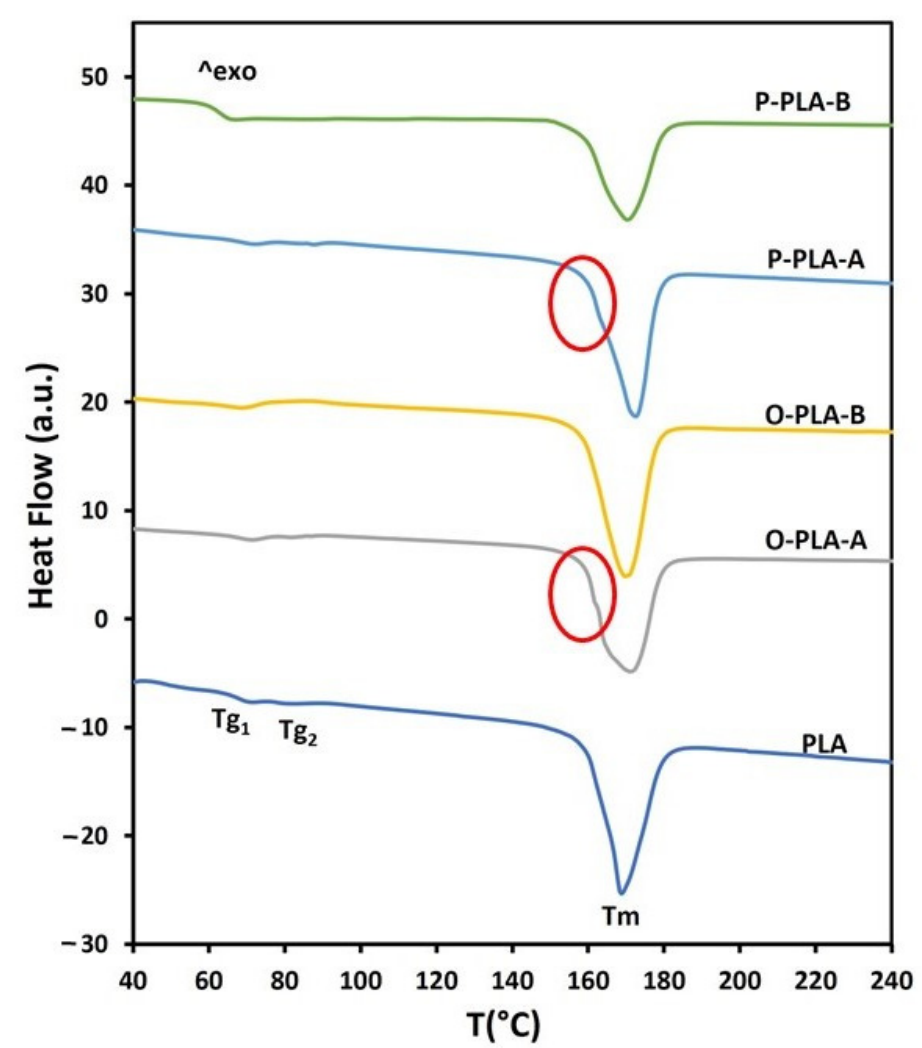

Figure 4. DSC thermograms for neat and functionalized PLA flat tapes obtained by reactive extrusion.

Table 6 lists several characteristic parameters established from DSC thermograms, such as glass transition temperature $\left(\mathrm{T}_{\mathrm{g}}\right)$, melting temperature $\left(\mathrm{T}_{\mathrm{m}}\right)$, melting enthalpy $\left(\Delta \mathrm{H}_{\mathrm{m}}\right)$, and degree of crystallinity $\left(\mathrm{X}_{\mathrm{c}}\right)$ obtained from the first heating program. Polymer crystallinity refers to the alignment of the polymer molecular chains and can affect optical, mechanical, and thermal properties after processing upon cooling from melting temperature and applying mechanical stretching. Therefore, after calculating the crystallinity degree of PLA flat tapes (Table 6), there can be discerned an increase in crystallinity after reaction with the alkoxysilanes, being enhanced with the incorporation of higher contents. Therefore, the incorporation of alkoxysilanes into the PLA matrix increases crystallization probably because of the appearance of nucleation points [46]. Moreover, as reported in Table 2, alkoxysilane incorporations into the PLA matrix allowed higher draw ratios for flat tape processing, suggesting a lubricant effect that enabled a greater segmental motion. Such a rheological effect provided higher longitudinal alignment through stretching forces and, consequently, an increase in the crystallinity [47-49]. Therefore, PLA samples with a higher incorporation of functional moieties reached higher crystallinity degrees, possibly owing to both nucleation effect at the coupling sites and higher draw ratio appliance, increasing from $47 \%$ for pure PLA to values close to $56 \%$ for samples with the highest concentrations of alkoxy derivatives.

On the other hand, the relationship between the degree of disintegration under composting conditions in the different samples of neat PLA and modified PLA can be estimated through their crystallinity. The previous literature has shown in multiple studies that an increase in crystallinity can lead to a delay in the biodegradation processes [50-52]. These biological processes are normally carried out by lipases, proteases, and esterases secreted from microorganisms in soil compost, and they have a greater facility to act in amorphous domains. However, multiple studies show that despite considerably increasing the crystallinity of a PLA, the delay in the disintegration processes is only a few days. For example, Balart et al. [53] reported a crystallinity in modified PLA with the addition of lignocellulosic fillers and bio plasticizers of twice the initial value. However, the degree of disintegration was delayed by only 14 days. In another work, Dominguez-Candela et al. [54] reported an 
increase of more than 53\% in PLA crystallinity when introducing an organic bio plasticizer, but, a disintegration of more than $90 \%$, which is considered by the UNE 20,200 standard as a biodegradable material, was obtained only 3 days later. Therefore, in view of the previous results, and given that in the present study, there is only a $10.6 \%$ increase in crystallinity concerning neat PLA, it can be affirmed that a subsequent disintegration process would be practically unaffected, considering the PLA modified by REX as totally biodegradable.

Figure 5 displays thermogravimetric analysis (TGA) for neat and functionalized PLA samples. In general, the results confirmed that PLA functionalized with different alkoxysilane contents presented similar degradation temperatures to neat PLA, which agrees with previous studies [40,42]. However, when TGA results were analyzed in detail (inset Figure 5 and Table 7), slight variations in thermal stabilities were observed. More specifically, PLA samples modified with low alkoxysilane concentrations, O-PLA-A and P-PLA-A, displayed similar thermal stability to neat PLA, breaking down at temperatures around $364-362{ }^{\circ} \mathrm{C}$, whereas higher organosilane contents showed slightly lower decomposition temperatures $\left(356-358^{\circ} \mathrm{C}\right)$. As evidenced by $1 \mathrm{H}-\mathrm{NMR}$ and SEC analyses, these small changes may be associated with ester-alkoxysilane exchange reactions, which occurs at high temperature, causing chain scissions via C-H hydrogen transfer reactions [36,54-57]. Consequently, lower molar weights and, therefore, lower thermal stabilities were obtained compared to neat PLA.

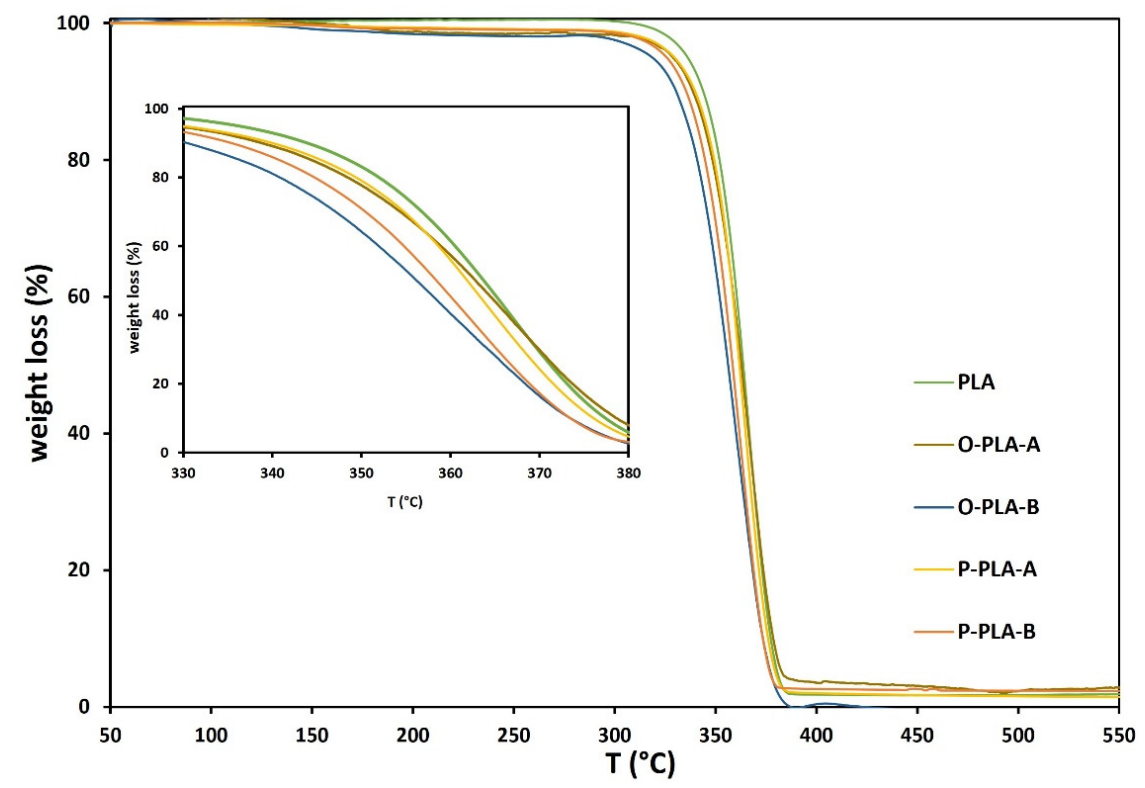

Figure 5. DSC thermograms for neat and functionalized PLA flat tapes obtained by reactive extrusion.

Table 7. Main thermal parameters of neat and functionalized PLA flat tapes by reactive extrusion obtained by TGA analysis.

\begin{tabular}{cccc}
\hline Sample & $\mathrm{T}_{\mathbf{0}}\left({ }^{\circ} \mathbf{C}\right)$ & $\mathrm{T}_{\mathbf{5 0}}\left({ }^{\circ} \mathbf{C}\right)$ & $\mathrm{T}_{\mathbf{f}}\left({ }^{\circ} \mathbf{C}\right)$ \\
\hline PLA & 292 & 364 & 385 \\
O-PLA-A & 294 & 363 & 385 \\
O-PLA-B & 292 & 356 & 387 \\
P-PLA-A & 298 & 362 & 385 \\
P-PLA-B & 298 & 358 & 380
\end{tabular}

$\mathrm{T}_{0}$ : starting degradation temperature, $\mathrm{T}_{50}$ : temperature when $50 \%$ mass is degraded, and $\mathrm{T}_{\mathrm{f}}$ : final degradation temperature.

The mechanical properties of neat and functionalized PLA flat tape samples were evaluated using an Instron mechanical testing machine. As shown in Table 8, results confirmed that the covalent incorporation of functional moieties into the PLA matrix did 
not reduce the inherent PLA mechanical properties. More specifically, Young's modulus, tensile strength at break, elongation at break, and dimensions of the flat tape samples were gathered in Table 8 .

Table 8. Mechanical properties (Young's modulus, tensile strength, and elongation at break), draw ratio (DR), and dimensions of neat and functionalized PLA flat tape samples.

\begin{tabular}{cccccc}
\hline Sample & DR & $\begin{array}{c}\text { Dimensions }(\mathbf{m m}) \\
\text { (Width } \times \\
\text { Thickness) }\end{array}$ & $\begin{array}{c}\text { Tensile Strength } \\
\text { at Break } \\
\mathbf{( M P a )}\end{array}$ & $\begin{array}{c}\text { Young's } \\
\text { Modulus } \\
\mathbf{( G P a )}\end{array}$ & $\begin{array}{c}\text { Elongation } \\
\text { at Break } \\
\mathbf{( \% )}\end{array}$ \\
\hline PLA & 4.5 & $2.70 \times 0.14$ & $157 \pm 10$ & $4.6 \pm 0.1$ & $40.2 \pm 2.6$ \\
O-PLA-A & 5.5 & $2.34 \times 0.13$ & $238 \pm 5$ & $5.1 \pm 0.1$ & $30.9 \pm 1.0$ \\
O-PLA-B & 6.6 & $2.40 \times 0.14$ & $215 \pm 10$ & $4.8 \pm 0.2$ & $31.9 \pm 2.7$ \\
P-PLA-A & 5.5 & $2.32 \times 0.13$ & $212 \pm 15$ & $5.1 \pm 0.1$ & $29.4 \pm 3.9$ \\
P-PLA-B & 6.2 & $2.37 \times 0.14$ & $177 \pm 8$ & $4.9 \pm 0.1$ & $23.4 \pm 2.7$ \\
\hline
\end{tabular}

As listed in Table 8, results confirmed the non-detrimental influence on mechanical properties when functional moieties were grafted into the PLA matrix. In this sense, functionalized samples depicted slightly superior tensile strength and Young's modulus, as well as lower elongation at break than neat PLA, which is related to the application of higher draw ratios and, consequently, superior longitudinal alignment of polymer molecular chains [58]. According to DSC results, the presence of alkoxysilanes into the PLA backbone caused a lubricant effect that allowed a more severe drawing treatment, reaching greater ordered crystalline structures and, consequently, increasing the Young's modulus. This lubricant effect was more pronounced when the alkoxysilane content was raised, allowing the application of draw ratios up to 6.2 and 6.6 for O-PLA-B and P-PLA-B, respectively $[23,40,42,43]$. Conversely, the highest alkoxysilane concentrations and draw ratios did not report the highest Young's modulus. Specifically, in the case of O-PLA-B, this fact may be associated with the scission chains caused by ester-alkoxysilane exchange reactions, which slightly reduce the molar weight, thermal stability, and, finally, mechanical behavior of PLA flat tapes [42,59]. For the P-PLA-B sample, based on ICP and NMR results, higher phenyltriethoxysilane led to the formation of highly silicon condensed species acting as particle aggregates and, consequently, as defects in the polymer matrix. Therefore, functionalized PLA samples obtained using 1.3\% alkoxysilane concentration, O-PLA-A, showed the best mechanical properties, reaching values of Young's modulus and elongation at break close to $5.1 \mathrm{GPa}$ and $30 \%$, respectively.

Hydroxyl end groups afford an opportunity to transform, through chemical modification, partial wettability of PLA into a low surface energy polymer, thus yielding hydrophobicity. This approach was carried out by functionalization of the PLA backbone with different alkoxysilanes in the molten state. The static water contact angle (WCA) for neat and hydrophobized PLA flat tapes was measured to evaluate the level of hydrophobicity attained after modification.

Figure 6 shows contact angle values obtained for neat and grafted PLA using water as the test liquid, providing a contact angle average value of $68.6^{\circ}$ for neat PLA. This average value is in concordance with a previous study reported by Jordá-Vilaplana et al. [60]. Taking into account that a contact angle over $90^{\circ}$ is considered a hydrophobic surface, and values lower than $30^{\circ}$ are regarded as hydrophilic surfaces [61], untreated PLA shows a slightly hydrophobic surface behavior. As shown in Figure 6, grafting PLA with low surface energy components, such as $\mathrm{Ph}-\mathrm{Si}(\mathrm{OEt})_{3}$ and Oct-Si $(\mathrm{OEt})_{3}$, minimizes the polymer surface free energy, giving place to an increase in the hydrophobicity [23]. More specifically, in agreement with its higher non-polar nature, PLA grafted with Oct-Si(OEt) 3 showed a greater contact angle, achieving a WCA of $82.2^{\circ}$ and therefore an increase in the hydrophobicity of almost $20 \%$ compared with neat PLA. Relating the results shown in the hydrobicity and mechanical tests, it appears that the functionalized samples, on the one hand, possess higher hydrophobicity and on the other hand superior mechanical strength 
properties due to the superior longitudinal alignment of polymer molecular chains, as Yan et al. demonstrated [58]. In addition, the insertion of the polar groups present in molecules such as Oct-Si $(\mathrm{OEt})_{3}$ may lead to a higher interaction between PLA molecules, restricting their mobility and increasing the mechanical properties.

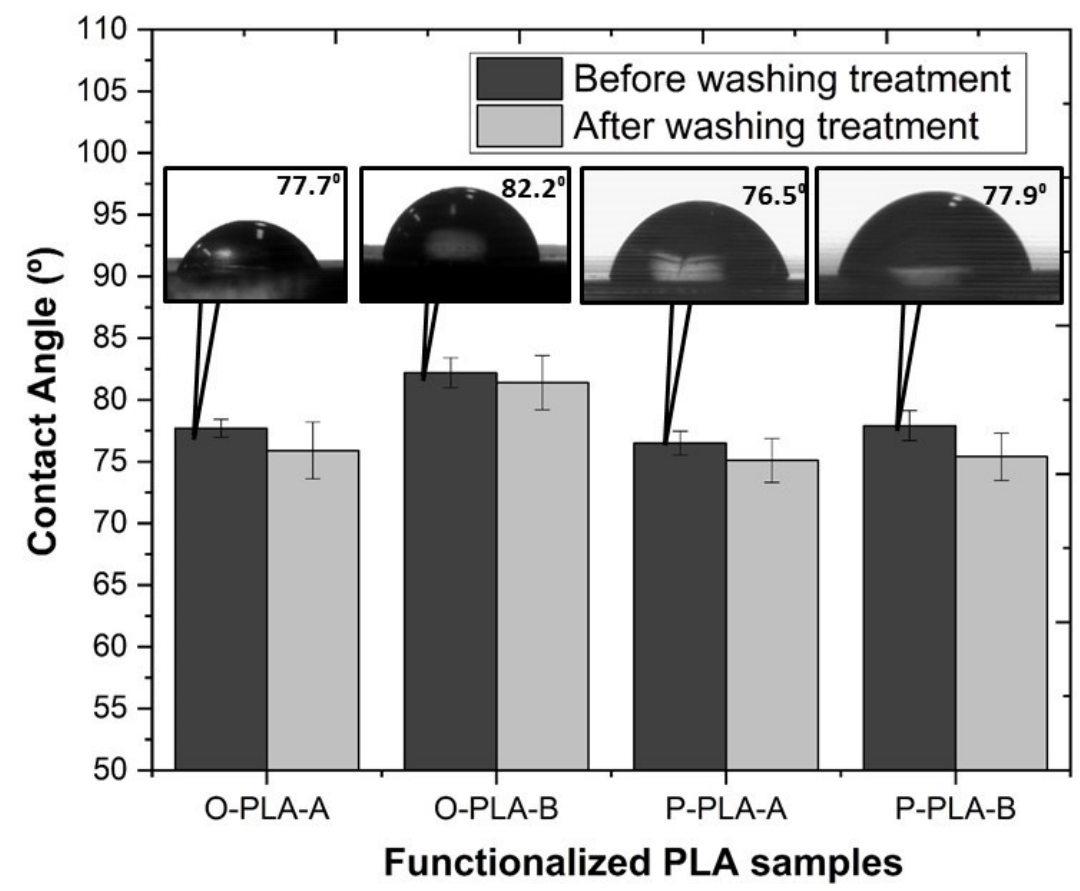

Figure 6. Variation of the water contact angle on the neat and functionalized PLA flat tape samples before and after washing treatment.

Aiming at verifying the stability of the grafted alkoxysilanes by the formation of new covalent bonds, samples were treated in hot water $\left(\mathrm{T}=80{ }^{\circ} \mathrm{C}\right)$ for $24 \mathrm{~h}$ under stirring conditions. The results showed that after washing treatment, WCA remained almost invariable, confirming the formation of stable and irreversible covalent bonds between PLA backbone and alkoxysilanes molecules through exchange reactions.

\section{Conclusions}

PLA chemical modification by alkoxysilanes in the molten state allowed the improvement of its native hydrophobicity and mechanical properties. After the reactive extrusion process, ICP-OES analyses confirmed the presence of alkoxy derivatives into the PLA matrix. ${ }^{1} \mathrm{H}$ NMR spectra confirmed the effective grafting process by exchange reactions. In addition, ${ }^{1} \mathrm{H}$ NMR results agreed with size exclusion chromatography analyses (SEC), which evidenced a slight reduction in molar mass values for functionalized PLA, being associated with chain scissions induced by ester-alkoxysilane exchange reactions at high temperature.

After evaluating thermal properties, flat tapes of neat PLA and PLA grafted with low alkoxysilanes concentrations displayed two small glass transition temperature peaks, which are associated with the formation of two regions with different crystallinity levels as a result of the drawing process. However, for higher alkoxysilanes concentrations, only one glass transition peak was observed at lower temperatures, which is associated with a uniform drawing process thanks to the creation of nucleating points and a lubricant effect. Similar observations were obtained regarding melting temperatures. Finally, the crystallinity degree was enhanced with the incorporation of higher contents of alkoxysilanes into the PLA matrix, due to the appearance of nucleation points.

Mechanical properties evaluation displayed an enhancement on tensile strength and Young's modulus in all cases, which is associated with the increase in the crystallization 
degree. However, the highest alkoxysilane concentrations did not report the highest values; in the case of O-PLA-B, it may be associated with the scission chains caused by esteralkoxysilane exchange reactions, whereas for the P-PLA-B sample, it may be associated with the formation of highly silicon condensed species acting as particle aggregates and, consequently, as defects in the polymer matrix. Therefore, PLA samples obtained using $1.3 \%$ alkoxysilane concentration (O-PLA-A) showed the best mechanical properties, reaching values of Young's modulus and elongation at break close to $5.1 \mathrm{GPa}$ and $30 \%$, respectively.

Finally, water contact angle values showed a clear variation depending on the type of alkoxysilane and concentration used, obtaining the highest hydrophobicity when $3.0 \mathrm{wt} \%$ of Oct-Si(OEt) ${ }^{3}$ was incorporated (O-PLA-B) into the polymer matrix. Furthermore, after applying a washing treatment, similar WCA values were obtained, confirming the stability of the grafted alkoxysilanes by the formation of stable and irreversible covalent bonds between PLA backbone and alkoxysilanes molecules.

Supplementary Materials: The following are available online at https:/ /www.mdpi.com/article/10 .3390/polym13152475/s1, Figure S1: Reaction scheme of the PLA modification with (3-glycidyloxypro pyl)trimethoxysilane and (b) 1H NMR of raw and mod-ified PLA different with concentration of (3-glycidyloxypropyl)trimethoxysilane: 1.3 and $2.7 \mathrm{wt} \%$, Figure S2: (a) Reaction scheme of the PLA modification with phenyltriethoxysilane and titanium phenoxide, (b) 1H NMR of raw and modified PLA with phenyltriethoxysilane and titanium phenoxide: P-PLA-B and PT-PLA-B.

Author Contributions: Conceptualization, E.T., A.G. and R.M.; Methodology, E.T., A.G., N.G.-B. and R.M.; Validation, E.T., A.G., N.G.-B. and M.M.; Formal Analysis, E.T., A.G. and N.G.-B.; Investigation, E.T., A.G., N.G.-B. and M.M.; Resources, A.G. and A.V.-L.; Data Curation, E.T.; Writing—original draft, E.T., A.G. and N.G.-B.; Writing—review and editing, E.T., A.G. and V.F.; Visualization, V.F.; Supervision, V.F. and A.V.-L.; Project Administration, E.T. and A.G.; Funding Acquisition, E.T., A.G., R.M., V.F. and A.V.-L. All authors have read and agreed to the published version of the manuscript.

Funding: This research work was funded by the Conselleria d'Economia Sostenible, Sectors Productius, Comerç i Treball de la Generalitat Valenciana through IVACE. Project references: GREENFILS, IMAMCI/2019/1 and BIOREX, IMAMCI/2020/1.

Institutional Review Board Statement: Not applicable.

Informed Consent Statement: Not applicable.

Acknowledgments: The authors would like to thank IVACE for the financial support and Véronique Bounor-Legaré et al. from the University of Lyon for the technical support.

Conflicts of Interest: The authors declare no conflict of interest.

\section{References}

1. Plastics Europe and European Association of Plastics Recycling and Recovery Organisations (EPRO). 2019. Available online: https: //www.plasticseurope.org/application/files/9715/7129/9584/FINAL_web_version_Plastics_the_facts2019_14102019.pdf (accessed on 30 April 2021).

2. European Environment Agency. The Plastic Waste Trade in the Circular Economy. 2019. Available online: https://www.eea. europa.eu/themes/waste/resource-efficiency/the-plastic-waste-trade-in (accessed on 31 May 2021).

3. Sintim, H.; Bandopadhyay, S.; English, M.E.; Bary, A.I.; DeBruyn, J.M.; Schaeffer, S.M.; Miles, C.A.; Reganold, J.P.; Flury, M. Impacts of biodegradable plastic mulches on soil health. Agric. Ecosyst. Environ. 2018, 273, 36-49. [CrossRef]

4. Haider, T.; Völker, C.; Kramm, J.; Landfester, K. Plastics of the Future? The Impact of Biodegradable Polymers on the Environment and on Society. Angew. Chem. Int. Ed. 2018, 58, 50-62. [CrossRef] [PubMed]

5. Formela, K.; Zedler, L.; Hejna, A.; Tercjak, A. Reactive Extrusion of Bio-Based Polymer Blends and Composites. Curr. Trends Future Dev. 2018, 12, 24-57.

6. The Global Bio-Based Polymer Market 2019-A Revised View on a Turbulent and Growing Market. Bio-Based News. 2020. Available online: http:/ / news.bio-based.eu/the-global-bio-based-polymer-market-2019-a-revised-view-on-a-turbulent-andgrowing-market/ (accessed on 28 June 2021).

7. European Bioplastics, Nova-Institute. 2019. Available online: https://www.european-bioplastics.org/market/ (accessed on 30 April 2021).

8. Narancic, T.; Cerrone, F.; Beagan, N.; O'Connor, K.E. Recent Advances in Bioplastics: Application and Biodegradation. Polymers 2020, 12, 920. [CrossRef] [PubMed] 
9. Lunt, J. Large-scale production, properties and commercial applications of polylactic acid polymers. Polym. Degrad. Stabil. 1998, 59, 145-152. [CrossRef]

10. Bio-Sourced Biodegradable PLA Fibres Will Replace Polyester in Textiles. Bioplastics News. 2017. Available online: https: / / bioplasticsnews.com/2017/08/04/bio-sourced-biodegradable-pla-fibres-polyester-textiles/ (accessed on 28 June 2021).

11. Radicci Company. Available online: https://www.radicigroup.com/en/products/fibres-and-nw/poy-starlight/biopolymercornleaf (accessed on 31 May 2021).

12. Avinc, O.; Khoddami, A. Overview of Poly(Lactic Acid) (PLA) Fibre: Part I: Production, Properties, Performance, Environmental Impact, and End-Use Applications of Poly(Lactic Acid). Fibres 2009, 41, 391-401. [CrossRef]

13. Zhang, J.F.; Sun, X. Poly(Lactic Acid)-Based Bioplastics; Woodhead Publishing: Cambridge, UK, 2005; pp. $251-288$.

14. Farrington, D.W.; Lunt, J.; Davies, S.; Blackburn, R.S. Polylactic acid fibres. In Biodegradable and Sustainable Fibres; Blackburn, R.S., Ed.; Woodhead Publishing Limited: Cambridge, UK, 2005.

15. Auras, R.A.; Lim, L.T.; Selke, S.E.; Tsuji, H. Poly(Lactic Acid): Synthesis, Structures, Properties, Processing, and Applications. Part IV: Degradation and Environmental Issues; John Wiley Sons: Hoboken, NJ, USA, 2011.

16. Karst, D.; Hain, M.; Yang, Y. Care of PLA Textiles. Res. J. Text. Apparel 2009, 13, 69. [CrossRef]

17. Avinc, O.; Wilding, M.; Phillips, D. Investigation of the influence of different commercial softeners on the stability of poly(lactic acid) fabrics during storage. Polym. Degrad. Stab. 2010, 95, 214. [CrossRef]

18. Ma, M.; Zhou, W. Improving the hydrolysis resistance of poly(lactic acid) fiber by hydrophobic finishing. Ind. Eng. Chem. Res. 2015, 54, 2599-2605. [CrossRef]

19. Patankar, N.A. Mimicking the Lotus Effect: Influence of double roughness structures and slender pillars. Langmuir 2004, 20, 8209-8213. [CrossRef]

20. eCoatsolutions Company. Available online: https://www.eco-coatsolutions.com/greenhouse--solar-series-self-cleaning-nanoceramic-coatings.html (accessed on 31 May 2021).

21. Kaseema, M.; Fatimah, S.; Nashrah, N.; Gun Ko, Y. Recent progress in surface modification of metals coated by plasma electrolytic oxidation: Principle, structure, and performance. Prog. Mater. Sci. 2021, 117, 100735. [CrossRef]

22. Hamad, K.; Gun Ko, Y.; Kaseem, M.; Deri, F. Effect of acrylonitrile-butadiene-styrene on flow behavior and mechanical properties of polylactic acid/low density polyethylene blend. Asia Pac. J. Chem. Eng. 2014, 9, 349-353. [CrossRef]

23. Hahladakis, J.N.; Costas, A.V.; Weber, R.; Iacovidou, E.; Purnell, P. An overview of chemical additives present in plastics: Migration, release, fate and environmental impact during their use, disposal and recycling. J. Hazard. Mater. 2018, 344, 179-199. [CrossRef] [PubMed]

24. Giri, P.; Tambe, C.; Narayan, R. Using Reactive Extrusion to Manufacture Greener Products: From Laboratory Fundamentals to Commercial Scale. In Biomass Extrusion and Reaction Technologies: Principles to Practices and Future Potential; American Chemical Society: Washington, DC, USA, 2018; Volume 1304, pp. 1-23.

25. Marinho, J.F.; Braga, N.F.; Krohn, A.; Myata, F.S.; Silveira, L.H.; Cabral Neto, A.; Fechine, G.J.M. Melt Processing of Polymer Biocomposites. Polímeros 2015, 25, 133-136. [CrossRef]

26. Formela, K.; Hejna, A.; Haponiuk, J.; Tercjak, A. In Situ Processing of Biocomposites via Reactive Extrusion; Ray, D., Ed.; Woodhead Publishing: Cambridge, UK, 2017; Volume 8, pp. 195-246.

27. Liao, J.; Brosse, N.; Hoppe, S.; Du, G.; Zhou, X.; Pizzi, A. One-step compatibilization of poly(lactic acid) and tannin via reactive extrusion. Mater. Des. 2020, 191, 108603. [CrossRef]

28. Nahum, T.; Dodiuk, H.; Dotan, A.; Kenig, S.; Lellouche, J.P. Superhydrophobic durable coating based on UV-photoreactive silica nanoparticles. J. Appl. Polym. Sci. 2014, 131, 41122. [CrossRef]

29. Kchaou, M.; Torres, E.; Ylla, N.; Colella, M.; Da Cruz-Boisson, F.; Cassagnau, P.; Espuche, E.; Bounor-Legaré, V. Enhanced Hydrophobicity and Reduced Water Transport Properties in Alkylalkoxysilane Modified Poly(Butylene Terephthalate) Using Reactive Extrusion. Mater. Chem. Phys. 2019, 223, 597-606. [CrossRef]

30. Tam, J.; Feng, B.; Ikuhara, Y.; Ohta, H.; Erb, U. Crystallographic orientation-Surface energy-Wetting property relationships of rare earth oxides. J. Mater. Chem. A 2018, 38, 1-6. [CrossRef]

31. Schondelmaier, D.; Cramm, S.; Klingeler, R.; Morenzin, J.; Zilkens, C.; Eberhardt, W. Orientation and self-assembly of hydrophobic fluoroalkylsilanes. Langmuir 2002, 18, 6242-6245. [CrossRef]

32. Vink, E.H.T.; Rábago, K.R.; Glassner, D.A.; Gruber, P.R. Applications of life cycle assessment to NatureWorks ${ }^{\mathrm{TM}}$ polylactide (PLA) production. Polym. Degrad. Stab. 2003, 80, 403-419. [CrossRef]

33. Gogolewski, S.; Pennings, A. Resorbable materials of poly(L-lactide). II. Fibers spun from solutions of poly(L-lactide) in good solvents. J. Appl. Polym. Sci. 1983, 28, 1045-1061. [CrossRef]

34. Ferri, J.M.; Fenollar, O.; Jorda-Vilaplana, A.; García-Sanoguera, D.; Balart, R. Effect of Miscibility on Mechanical and Thermal Properties of Poly(Lactic Acid)/Polycaprolactone Blends. Polym. Int. 2016, 65, 453-463. [CrossRef]

35. Xie, Y.; Hill, C.A.S.; Xiao, Z.; Militz, H.; Mai, C. Silane Coupling Agents used for Natural Fiber/Polymer Composites: A Review. Compos. Part A 2010, 41, 806-819. [CrossRef]

36. Issa, A.A.; Luyt, A.S. Kinetics of Alkoxysilanes and Organoalkoxysilanes Polymerization: A Review. Polymers 2019, 11, 537. [CrossRef]

37. Chumeka, W.; Pasetto, P.; Pilard, J.-F. Bio-based triblock copolymers from natural rubber and poly(lactic acid): Synthesis and application in polymer blending. Polymer 2014, 55, 4478-4487. [CrossRef] 
38. He, Z.; Jiang, L.; Chuan, Y.; Li, H.; Yuan, M. Ring-Opening Polymerization of L-Lactic Acid O-Carboxyanhydrides Initiated by Alkoxy Rare Earth Compounds. Molecules 2013, 18, 12768-12776. [CrossRef]

39. Kricheldorf, A.R.; Hachmann-Thiessen, H.; Schwarz, G. Telechelic and Star-Shaped Poly(L-lactide)s by Means of Bismuth(III) Acetate as Initiator. Biomacromolecules 2004, 5, 492-496. [CrossRef] [PubMed]

40. Popelka, S.; Rypácek, F. Synthesis of polylactide with thiol end groups. Collect. Czech. Chem. Commun. 2003, 68, 1131-1140. [CrossRef]

41. Castro-Aguirre, E.; Iñiguez-Franco, F.; Samsudin, H.; Fang, X.; Auras, R. Poly(lactic acid)—Mass production, processing, industrial applications, and end of life. Adv. Drug Deliv. Rev. 2016, 107, 333-366. [CrossRef]

42. Taubner, V.; Shishoo, R. Influence of processing parameters on the degradation of poly(L-lactide) during extrusion. J. Appl. Polym. Sci. 2001, 79, 2128-2135. [CrossRef]

43. Meng, X.; Nguyen, N.; Tekinalp, H.; Lara-Curzio, E.; Ozcan, S. Supertough PLA-silane nanohybrids by in situ condensation and grafting. ACS Sustain. Chem. Eng. 2018, 6, 1289-1298. [CrossRef]

44. Zhang, J.; Duan, Y.; Tsuji, H.; Noda, I.; Ozaki, Y. Structural Changes and Crystallization Dynamics of Poly(l-lactide) during the Cold-Crystallization Process Investigated by Infrared and Two-Dimensional Infrared Correlation Spectroscopy. Macromolecules 2004, 37, 6433-6439. [CrossRef]

45. Xu, R.; Xie, J.; Lei, C. Influence of Melt-Draw Ratio on the Crystalline Behaviour of a Polylactic Acid Cast Film with a Chi Structure. RSC Adv. 2017, 7, 39914-39921. [CrossRef]

46. Coltelli, M.-B.; Mallegni, N.; Rizzo, S.; Cinelli, P. Improved Impact Properties in Poly(lactic acid) (PLA) Blends Containing Cellulose Acetate (CA) Prepared by Reactive Extrusion. Materials 2019, 12, 270. [CrossRef] [PubMed]

47. Xu, Y.Q.; Qu, J.P. Mechanical and rheological properties of epoxidized soybean oil plasticized poly (lactic acid). J. Appl. Polym. Sci. 2009, 112, 3185-3191. [CrossRef]

48. Lee, J.C.; Choi, M.-C.; Choi, D.-H.; Ha, C.-S. Toughness Enhancement of Poly(Lactic Acid) through Hybridisation with EpoxideFunctionalized Silane via Reactive Extrusion. Polym. Degrad. Stab. 2019, 160, 195-202. [CrossRef]

49. Ku Marsilla, K.I.; Verbeek, C.J.R. Modification of poly(lactic acid) using itaconic anhydride by reactive extrusion. Eur. Polym. J. 2015, 67, 213-223. [CrossRef]

50. Tokiwa, Y.; Calabia, B.P. Biodegradability and biodegradation of poly(lactide). Appl. Microbiol. Biotechnol. 2006, 72, $244-251$. [CrossRef]

51. Gil-Castell, O.; Badia, J.; Kittikorn, T.; Strömberg, E.; Martínez-Felipe, A.; Ek, M.; Karlsson, S.; Ribes-Greus, A. Hydrothermal ageing of polylactide/sisal biocomposites. Studies of water absorption behaviour and Physico-Chemical performance. Polym. Degrad. Stab. 2014, 108, 212-222. [CrossRef]

52. Ray, S.S.; Yamada, K.; Ogami, A.; Okamoto, M.; Ueda, K. New Polylactide/Layered Silicate Nanocomposite: Nanoscale Control Over Multiple Properties. Macromol. Rapid Commun. 2002, 23, 943-947. [CrossRef]

53. Balart, J.F.; Montanes, N.; Fombuena, V.; Boronat, T.; Sánchez-Nacher, L. Disintegration in Compost Conditions and Water Uptake of Green Composites from Poly(Lactic Acid) and Hazelnut Shell Flour. J. Polym. Environ. 2017, 26, 701-715. [CrossRef]

54. Dominguez-Candela, I.; Ferri, J.M.; Cardona, S.C.; Lora, J.; Fombuena, V. Dual Plasticizer/Thermal Stabilizer Effect of Epoxidized Chia Seed Oil (Salvia hispanica L.) to Improve Ductility and Thermal Properties of Poly(Lactic Acid). Polymers 2021, 13, 1283. [CrossRef]

55. Garlotta, D.A. Literature Review of Poly(Lactic Acid). J. Polym. Environ. 2001, 9, 63-84. [CrossRef]

56. Al-Itry, R.; Lamawar, K.; Maazouz, A. Improvement of thermal stability, rheological and mechanical properties of PLA, PBAT and their blends by reactive extrusion with functionalized epoxy. Polym. Degrad. Stabil. 2012, 10, 1898-1914. [CrossRef]

57. McNeill, I.C.; Leiper, H.A. Degradation studies of some polyesters and polycarbonates. 1. Polylactide: Degradation under isothermal conditions, thermal degradation mechanism and photolysis of the polymer. Polym. Degrad. Stabil. 1985, 11, 309-326. [CrossRef]

58. Yan, Y.; Zhang, M.; Ju, Z.; Tam, P.Y.; Hua, T.; Younas, M.W.; Kamrul, H.; Hu, H. Poly(lactic acid) fibers, yarns and fabrics: Manufacturing, properties and applications. Text. Res. J. 2020, 91, 1-29.

59. Liv, S.; Tan, H.; Gu, J.; Zhang, Y. Silane Modified Wood Flour Blended with Poly(Lactic Acid) and Its Effects on Composite Performance. Bioresources 2015, 10, 5426-5439. [CrossRef]

60. Jordá-Vilaplana, A.; Fombuena, V.; García-García, D.; Samper, M.D.; Sánchez-Nácher, L. Surface modification of polylactic acid (PLA) by air atmospheric plasma treatment. Eur. Polym. J. 2014, 58, 23-33. [CrossRef]

61. Fombuena, V.; Balart, J.; Boronat, T.; Sánchez-Nácher, L.; Garcia-Sanoguera, D. Improving mechanical performance of thermoplastic adhesion joints by atmospheric plasma. Mater. Des. 2013, 47, 49-56. [CrossRef] 